\title{
Clinical characteristics and outcomes of critically ill patients with coronavirus disease 2019 with hypotension in China: a retrospective cohort study
}

\author{
Fengmei Guo ${ }^{1}$, Jianfeng $\mathrm{Xie}^{1}$, Wenjuan $\mathrm{Wu}^{2}$, Shusheng $\mathrm{Li}^{3}, \mathrm{Ming} \mathrm{Hu}^{4}$, Jinxiu $\mathrm{Li}^{5}$, Li Jiang ${ }^{6}$, Bin $\mathrm{Du}^{7}$, \\ Zhaohui Tong ${ }^{8}$, Haibo Qiu \\ ${ }^{1}$ Department of Critical Care Medicine, Zhongda Hospital, School of Medicine, Southeast University, Nanjing, China; ${ }^{2}$ Department of Critical Care \\ Medicine, Wuhan Jinyintan Hospital, Wuhan, China; ${ }^{3}$ Department of Critical Care Medicine, Tongji Hospital, Tongji Medical College Huazhong \\ University of Science and Technology, Wuhan, China; ${ }^{4}$ Department of Infection Disease, Wuhan Pulmonary Hospital, Wuhan, China; ${ }^{5}$ Department \\ of Critical Care Medicine, Shenzhen Third Hospital, Shenzhen, China; ${ }^{6}$ Department of Critical Care Medicine, Xuanwu Hospital, Capital Medical \\ University, Beijing, China; ${ }^{7}$ Medical ICU, Peking Union Medical College Hospital, Peking Union Medical College \& Chinese Academy of Medical \\ Sciences, Beijing, China; ${ }^{8}$ Department of Respiratory and Critical Care Medicine, Beijing Institute of Respiratory Medicine, Beijing Chaoyang \\ Hospital, Capital Medical University, Beijing, China \\ Contributions: (I) Conception and design: F Guo, H Qiu; (II) Administrative support: B Du; (III) Provision of study materials or patients: Z Tong; (IV) \\ Collection and assembly of data: W Wu, S Li, M Hu, J Li, L Jiang; (V) Data analysis and interpretation: F Guo; (VI) Manuscript writing: All authors; \\ (VII) Final approval of manuscript: All authors. \\ Correspondence to: Haibo Qiu, MD. Department of Critical Care Medicine, Zhongda Hospital, School of Medicine, Southeast University, 87 Dingiia \\ Bridge, Hunan Road, Gu Lou District, Nanjing 210009, China. Email: Haiboq2000@163.com.
}

Background: The characteristics of the coronavirus disease 2019 (COVID-19) patients with hypotension are still limited. We aim to describe the clinical features and outcomes of the patients.

Methods: This was a multicenter retrospective study of critically ill patients with COVID-19 from ICUs in 19 hospitals in China. All patients were followed up to day 28 or death, which came first. Clinical and outcome data were collected and analyzed. Patients were classified as early-onset or late-onset hypotension, and clinical characteristics and outcomes were compared.

Results: A total of 649 patients were included in the final analysis, and 240 (37.0\%) were hypotension patients. The median age of hypotension patients was 67 years (IQR, 60-73 years), and 159 (66.2\%) were male. $172(71.7 \%)$ of the hypotension patients had at least one comorbidity. The 28-day mortality of the patients with hypotension was $85.4 \%$, which was significantly higher than that of patients without hypotension. Compared with late-onset hypotension patients, the 28-day mortality of patients with earlyonset hypotension was significantly higher $(90.1 \%$ vs. $78.6 \%, \mathrm{P}=0.02)$.

Conclusions: Approximately one third critically ill COVID-19 patients progressed to hypotension. The mortality was significantly higher in hypotension patients than that in patients without hypotension. Compared with patients with late-onset hypotension, the mortality of patients with early-onset hypotension was significantly higher.

Keywords: Critically ill patients; coronavirus disease 2019 (COVID-19); hypotension; clinical features; outcomes

Submitted Nov 02, 2020. Accepted for publication Jun 22, 2021.

doi: 10.21037/apm-20-2172

View this article at: https://dx.doi.org/10.21037/apm-20-2172 


\section{Introduction}

The severe acute respiratory syndrome coronavirus 2 (SARS-CoV-2) and the disease it causes, coronavirus disease 2019 (COVID-19) has been initially identified in the Chinese city of Wuhan in December 2019 (1-3). Now, the virus has caused global outbreak and has affected thousands of people so far. A total number of 4,517,399 laboratoryconfirmed cases have been documented globally, including 308,515 deaths as of 16 May, 2020 (4). This rapidly evolving situation has created an unprecedented strain on many health care systems, and is an emerging health threat to all mankind.

The severity of the COVID-19 patients appears to vary, including asymptomatic infection, upper respiratory tract illness, pneumonia of different severity, and even death. Although most patients are thought to have a favorable prognosis, the outcome of the patients with severe illness would become significantly worse. Critically ill patients often have systemic involvement of multiple organs and may develop organ dysfunction in the disease course, encompassing acute respiratory distress syndrome (ARDS), hypotension, and acute kidney injury (AKI) (5-7), which is the main cause of poor prognosis. Certain epidemiological, clinical, and pathological features of COVID-19 have been recently reported (8-13). However, the characteristics of COVID-19 patients with hypotension were not well described. In this study, we present details of all critically ill COVID-19 patients with hypotension admitted to 19 hospitals who have experienced a definite outcome in China. We aim to describe the clinical features and outcomes of the patients, and explore risk factors of associated with in-hospital death. We present the following article in accordance with the STROBE reporting checklist (available at https://dx.doi.org/10.21037/apm20-2172).

\section{Methods}

\section{Data Sources and study participants}

This retrospective cohort study was a second analysis of a previous study which describe the characteristics of critically patients with COVID-19 (14). Patients admitted to one of the ICUs among the 19 hospitals between Jan 1 and Feb 28, 2020, were enrolled. All patients were diagnosed with COVID-19 according to World Health Organization interim guidance. All patients underwent nucleic acid testing by reverse transcription-polymerase chain reaction testing, and the results were positive for COVID-19. This study protocol was approved by each local institutional ethics committee.

Clinical data reported in this study included the followings: age, sex, medical comorbidities, clinical symptoms and signs, laboratory findings on ICU admission, treatment (including antiviral therapy, antibiotics, corticosteroid therapy, immunomodulators, vasoactive drug, continuous renal replacement therapy (CRRT) and respiratory support) during the ICU stay, and Day 28 prognosis in the ICU. Laboratory testing was performed according to the clinical care needs of the patient. Laboratory assessments consisted of a complete blood count, blood gas analysis, coagulation testing, assessment of liver and renal function, Troponin I (TNI), creatine kinase $(\mathrm{CK})$, creatine kinase muscle-brain isoform (CK$\mathrm{MB}), \mathrm{C}$-reactive protein (CRP), and procalcitonin. The study was conducted in accordance with the Declaration of Helsinki (as revised in 2013). The study was approved by Ethics Committee of Jin Yin-tan Hospital (KY-2020-10.02) and individual consent for this retrospective analysis was waived.

\section{Definitions}

Hypotension were defined as mean arterial pressure (MAP) lower than $65 \mathrm{mmHg}$, not reversed with fluid resuscitation, requiring vasopressors to maintain $\mathrm{MAP} \geq 65 \mathrm{mmHg}$, and the duration of vasoactive drug use was longer than 24 hours (15). AKI was diagnosed according to the KDIGO clinical practice guidelines and ARDS was diagnosed according to the Berlin Definition (16,17). All the critically ill COVID-19 patients were classified as early-onset hypotension or late-onset hypotension according to the median duration between ICU admission and diagnosis of hypotension. Lymphocytopenia was defined as a lymphocyte count of less than 1,500 cells per cubic millimeter.

\section{Statistical analysis}

Continuous variables with non-normal distribution were presented as median and IQR with 95\% CIs. Categorical variables were expressed as number of patients (percentage) with $95 \%$ CIs. Categorical data were compared using the $\chi^{2}$ test or the Fisher exact test. Non-normal distribution continuous data were compared using Mann-WhitneyWilcoxon test. Bivariate Cox proportional hazard ratio (HR) models were used to determine HRs and 95\% CIs between 
individual factors on the progression from hypotension to death. Survival curves were developed using the Kaplan-Meier method with log-rank test. The analyses regarding different factors were based on nonmissing data and imputed missing data. All tests were 2 -sided, and a $\mathrm{P}$ value less than 0.05 was considered statistically significant. All analyses were performed with SPSS, version 23.0 (IBM SPSS).

\section{Results}

\section{Demographic, epidemiologic, and baseline characteristics}

A total of 733 adult critically ill COVID-19 patients were admitted to ICUs in the 19 hospitals between Jan 1 and Feb 28, 2020. Of these patients, 324 (44.2\%) were diagnosed as hypotension. After excluding 84 patients who were diagnosed as hypotension within 24 hours of ICU admission, 649 patients were included in the final analysis, including $240(37.0 \%)$ patients with hypotension (Table 1). The median duration from symptom onset to hypotension was $18.2 \mathrm{~d}$ (IQR, 13-23 d), which is later than the onset of ARDS (Median $8.1 \mathrm{~d}$, IQR, 7-17 d). The median age of the patients with hypotension was 67 years (IQR, 6073 years), and 159 (66.2\%) were male. A total of 172 (71.7\%) hypotension patients had at least one comorbidity. The median (IQR) Acute Physiology and Chronic Health Evaluation (APACHE) II score of the patients with hypotension at ICU admission was 13.0 (9.0-16.0), and the median (IQR) Sequential Organ Failure Assessment (SOFA) score was 4.0 (2.0-8.0), both were significantly higher than the values of the patients without hypotension.

\section{Clinical characteristics, laboratory findings, and main treatments}

The most common symptoms of the patients with hypotension at onset were fever (206 patients, 85.8\%) and cough (180 patients, $75.0 \%$; Table 1). Compared with patients without hypotension, shortness of breath and fatigue were more common among patients with hypotension. Heart rate and respiratory rate on admission were both higher among patients with hypotension than patients without hypotension [96.0 (81.0-108.0) vs. 89.0 (80.0-100.0), $\mathrm{P}=0.01 ; 26.0$ (21.0-32.0) vs. 22.0 (20.0-26.0), $\mathrm{P}=0.00]$. There were many differences in laboratory findings on ICU admission between patients with hypotension and those without hypotension, including higher white blood cell, lower lymphocyte and $\mathrm{PaO}_{2} / \mathrm{FiO}_{2}$, as well as higher levels of total bilirubin, LDH, D-dimer, prothrombin time, creatinine, TNI, CK-MB, CRP, and procalcitonin (Table 1).

During ICU stay, 177 (73.8\%) patients with hypotension received antiviral therapy. Systemic glucocorticoids were given to 148 patients $(61.7 \%)$, and more than half of patients received immunomodulators. There was no difference in above drug interventions between patients with hypotension and without hypotension. Of the 240 patients with hypotension, 231 patients (96.2\%) progressed to ARDS. Although high-flow nasal cannula (HFNC) oxygen therapy was administered in 161 patients with hypotension (67.1\%) and noninvasive mechanical ventilation in $158(65.8 \%)$, invasive mechanical ventilation was required in 201 (83.8\%) patients with hypotension. As of the 201 intubated patients, $169(70.4 \%)$ patients were intubated within $48 \mathrm{~h}$ of the diagnosis of hypotension. At ICU admission, AKI developed in 71 patients $(29.6 \%)$, and aspartate aminotransferase or alanine aminotransferase greater than $40 \mathrm{U} / \mathrm{L}$ developed in 135 patients $(56.2 \%)$. More patients with hypotension received CRRT than patients without hypotension [64 (26.7\%) vs. 15 (3.7\%), $\mathrm{P}=0.00$; Table 1].

\section{Clinical outcomes}

As of 28 days after ICU admission, of the 240 critically ill COVID-19 patients with hypotension, 205 patients died, 16 have discharged from hospital, and 19 were still in hospital. The mortality of patients with hypotension was significantly higher than that of patients without hypotension ( $85.4 \%$ vs. $30.3 \%, \mathrm{P}=0.00$; Table 1, Figure 1$)$.

Compared with survivors of patients with hypotension, nonsurvivors were older and had higher APACHE II and lower $\mathrm{PaO}_{2} / \mathrm{FiO}_{2}$ ratio at admission to ICU. For patients with hypotension who died, the value of $\mathrm{LDH}, \mathrm{C}$-reactive protein, D-dimer, and creatinine were significantly elevated compared with patients with hypotension who survived. For survivors, more patients were tested negative for the virus during treatment than non-survivors $(34.3 \%$ vs. $7.8 \%$, $\mathrm{P}=0.00$; Table $\mathrm{S} 1$ ). The risk of COVID-19 nucleic acid positivity was 2.1 times higher in patients who died than those who survived (Figure S1). Mortality was significantly higher in patients who were treated with HFNC or noninvasive mechanical ventilation first than those were treated with intubation first (Figure 2). Compared with patients who initiated invasive mechanical ventilation more than $48 \mathrm{~h}$ before hypotension diagnosis, more patients died when the invasive mechanical ventilation initiated within $48 \mathrm{~h}$ of hypotension diagnose. When considering 
Table 1 Demographics and clinical characteristics of critically ill COVID-19 patients with hypotension

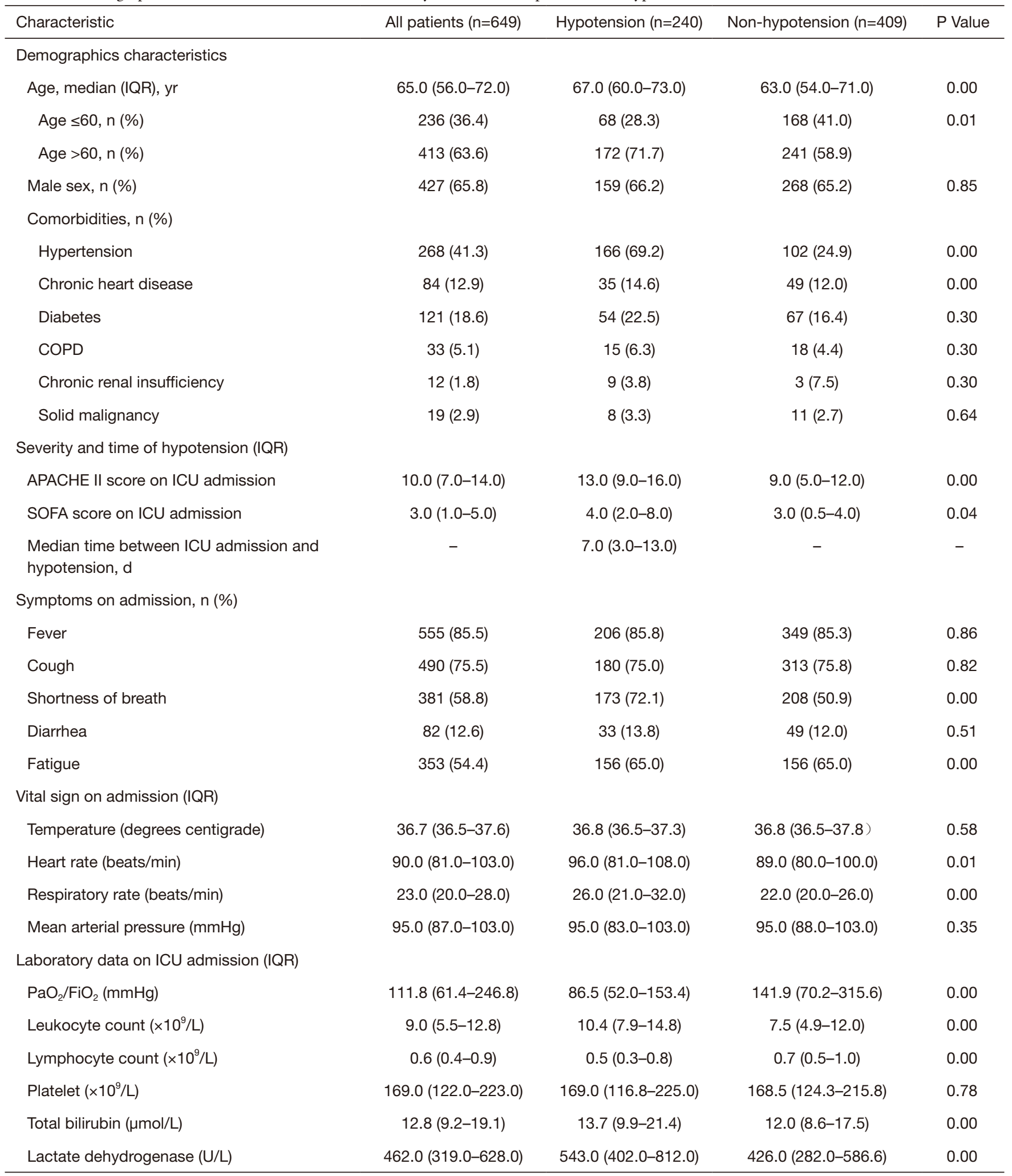

Table 1 (continued) 
Table 1 (continued)

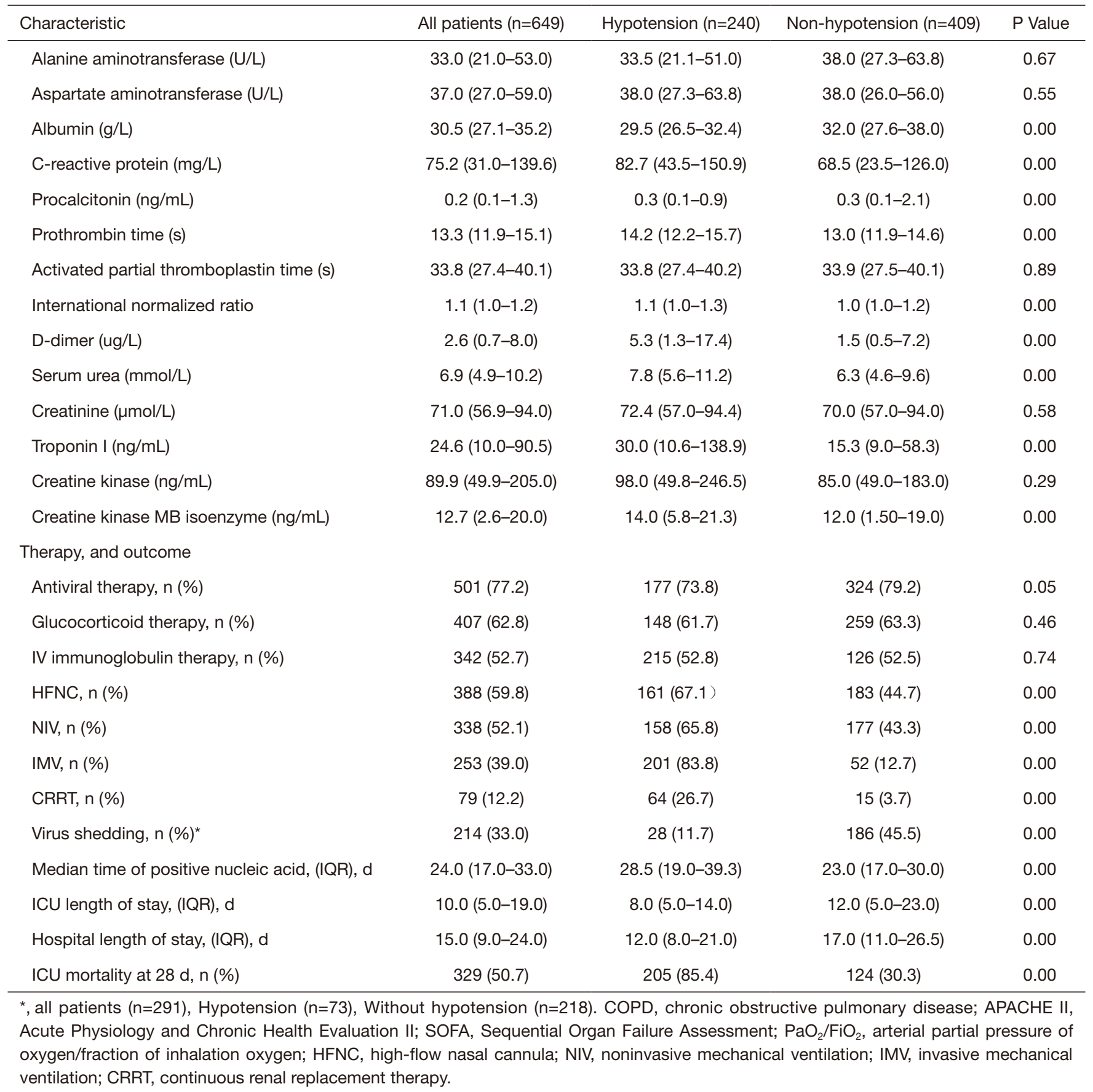

prognostic factors of the critically ill COVID-19 patients with hypotension, bivariate cox models showed that higher APACHE II score, lower $\mathrm{PaO}_{2} / \mathrm{FiO}_{2}$, elevated D-dimer and HFNC and noninvasive mechanical ventilation were associated with increased HR of death (Table 2).

\section{Compared patients with early-onset hypotension with patients with late-onset hypotension}

The median duration from ICU admission to diagnosis of hypotension was $7 \mathrm{~d}$ (IQR, 3.0-13.0 d), according to the time duration, 142 cases of the 240 critically ill COVID-19 


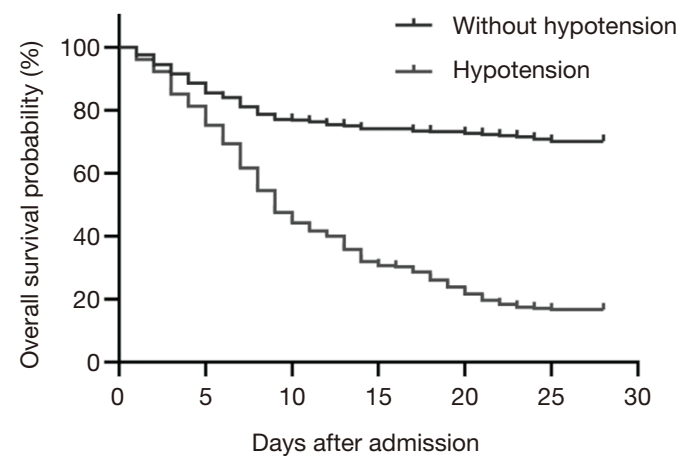

Figure 1 Survival curve in patients hospitalized with critically ill COVID-19 with and without hypotension.

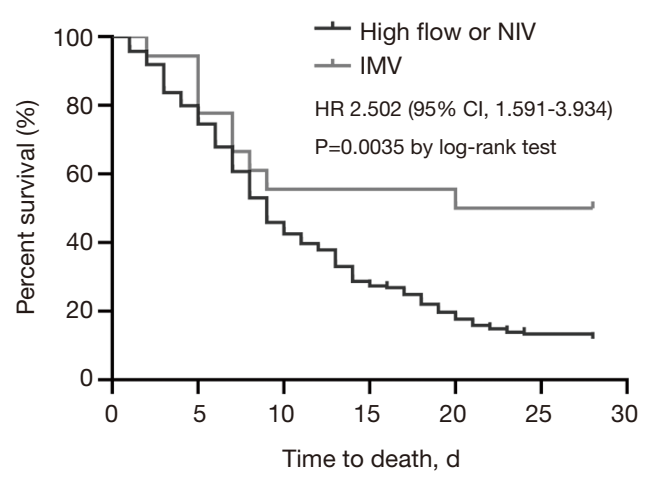

Figure 2 Survival curve in critically ill COVID-19 hypotension patients with different respiratory support. NIV, noninvasive mechanical ventilation; IMV, invasive mechanical ventilation.

Table 2 Bivariate cox regression of factors associated with in-hospital death in critically ill COVID-19 patients with hypotension

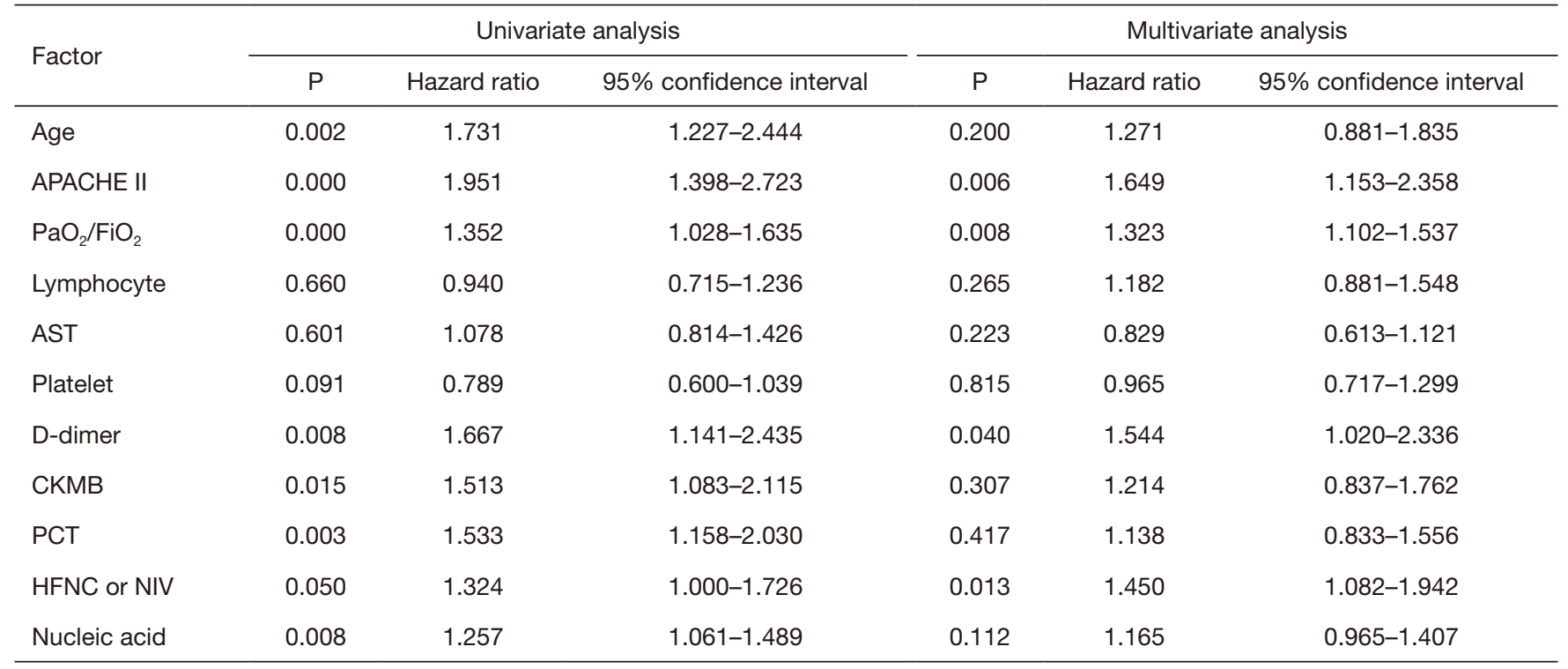

APACHE II, Acute Physiology and Chronic Health Evaluation II; AST, aspartate aminotransferase; CKMB, creatine kinase MB isoenzyme; PCT, procalcitonin; HFNC, high-flow nasal cannula; NIV, noninvasive mechanical ventilation.

patients with hypotension were classified as early-onset hypotension and 98 cases as late-onset hypotension (Table 3). The median (IQR) APACHE II score and the median (IQR) SOFA score on ICU admission did not differ between the two groups. $\mathrm{PaO}_{2} / \mathrm{FiO}_{2}$ on ICU admission was significantly lower among patients with early-onset hypotension than patients with late-onset hypotension [82.9 (52.6-118.9) vs. 109.1 (62.8-190.4), $\mathrm{P}=0.03$ ]. The median (IQR) LDH of the patients with early-onset hypotension on ICU admission was significantly higher than the values of the patients with late-onset hypotension [625.0 (432.0-870.5) vs. 462.0 (367.5-643.8), $\mathrm{P}=0.00$ ], so did TNI, CK and CKMB. Compared with patients with late-onset hypotension, the ICU mortality of patients with early-onset hypotension at 28 day was significantly higher $(90.1 \%$ vs. $78.6 \%, \mathrm{P}=0.02$; Table 3).

\section{Discussion}

Data on critically ill COVID-19 patients with hypotension is scare. In this study, we reported the clinical characteristics and risk factors associated with clinical outcomes in 
Table 3 Demographics and clinical characteristics of critically ill COVID-19 patients with hypotension according to the time at risk

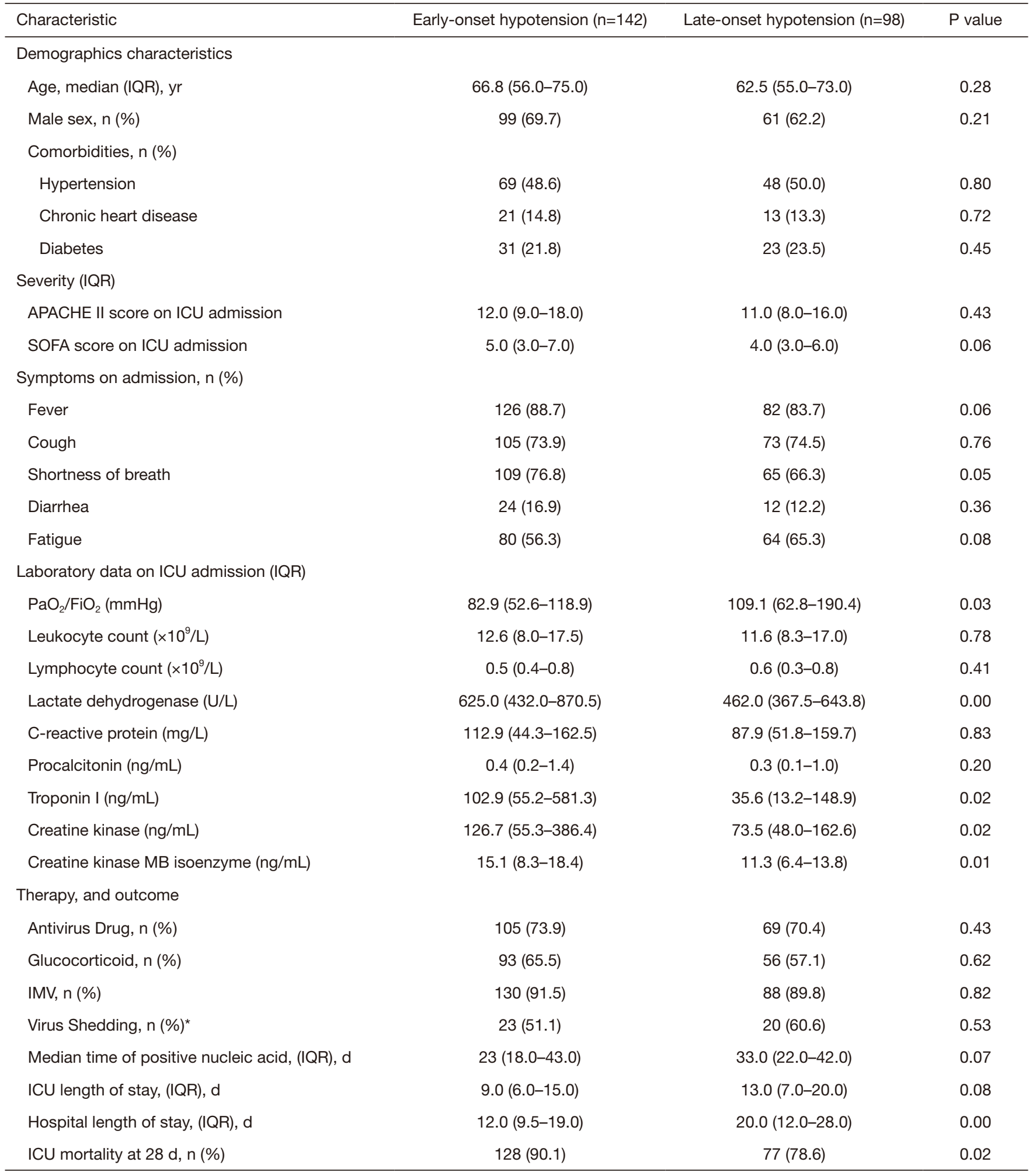

*, early-onset hypotension $(n=45)$, late-onset hypotension $(n=33)$. APACHE II, Acute Physiology and Chronic Health Evaluation II; SOFA, sequential organ failure assessment; $\mathrm{PaO}_{2} / \mathrm{FiO}_{2}$, arterial partial pressure of oxygen/fraction of inhalation oxygen; IMV, invasive mechanical ventilation. 
critically ill COVID-19 patients with hypotension. Data of the research was obtained from 649 patients with complete clinical course and established clinical outcomes. The results showed that approximately one third critically ill COVID-19 patients progressed to hypotension. More than three quarters of the patients with hypotension died at day 28 . The mortality was significantly higher in hypotension patients than that in patients without hypotension. Compared with patients with late-onset hypotension, the mortality of patients with early-onset hypotension was significantly higher. In addition, APACHE II score, lower $\mathrm{PaO}_{2} / \mathrm{FiO}_{2}$, elevated D-dimer, and HFNC and noninvasive mechanical ventilation were associated with increased HR of death.

Current studies showed, in accordance with other critically ill patients, COVID-19 patients often have systemic involvement of multiple organs during the disease course (18-20). Our results showed that approximately one third of the critically ill COVID-19 patients progressed to hypotension during the course of the disease. Previous researches reported cardiac complications are common in patients with pneumonia $(21,22)$. In the study, TNI increased in patients with hypotension and was higher than that in patients without hypotension, more than half of those with TNI increased died. Therefore, we speculate the potential myocardial injury may be one of the causes of hypotension. In addition, it is widely recognized that critically ill patients are susceptible to infections through various mechanisms, such as immunosuppression and mechanical ventilation (23). Secondary infections may be also an important cause of hypotension.

APACHE II score is a good severity marker for critically ill patients, and reflects the state and degree of multi-organ dysfunction. Current reports determined that critically ill COVID-19 patients often have respiratory system, the heart, kidney, liver, and coagulation system disorder during the disease course. our result was in accordance with previous studies about organ dysfunction, in which ARDS is the most common complication (24-26), and often followed by myocardial dysfunction and hypotension, and AKI. Sometimes multiple system involvement was observed even at the time of initial hospital admission, potentially leading to poor outcome. Therefore, APACHE II score was helpful in predicting hospital mortality in critically ill COVID-19 patients with hypotension (27).

Increased D-dimer indicates abnormal coagulation function. Viral infection and hypotension can activate coagulation cascade through various mechanisms, such as excessive inflammation, hypoxia $(5,7,19)$, leading to severe hypercoagulability and may predispose to thromboembolis, which may be one of the causes of morbidity and mortality death in COVID-19 patients with hypotension. A recent study showed $31 \%$ incidence of thrombotic complications in ICU patients with COVID-19 infections, of which CTPA and/or ultrasonography confirmed VTE in $27 \%$ and arterial thrombotic events in $3.7 \%$ (28). In view of this, monitoring and timely treatment towards coagulation abnormal may thereby reduce the risk of death of COVID-19 patients with hypotension.

The imbalance between oxygen supply and demand is the critical pathophysiological mechanism of hypotension. Shortness of breath and ARDS, the common symptom and complication of critically ill COVID-19 patients with hypotension, exacerbates the imbalance. So, proper respiratory support is not only an important treatment to correct hypoxia, but also a key treatment strategy for hypotension. Our result indicated HFNC and noninvasive mechanical ventilation was associated with increased HR of death. It is consistent with previous study that showed HFNC and noninvasive mechanical ventilation may be insufficient to manage ARDS $(24,29,30)$. More importantly, more patients in our studies died when invasive mechanical ventilation initiated late to within $48 \mathrm{~h}$ of hypotension diagnosis, indicating delayed intubation for COVID-19 patients with hypotension was associated with increased mortality. Therefore, it is especially critical to avoid delaying intubation and mechanical ventilation for any reason for critically ill COVID-19 patients with hypotension.

The duration of infectious virus replication affects not only decision making but also the patients condition. In the research, we found that the detectable SARS-CoV-2 RNA persisted for a median of 31 days in COVID-19 patients with hypotension, and sustained viral detection in samples was observed in both survivors and non-survivors. This is similar to MERS-CoV RNA detection in lower respiratory specimens which persisted positive for at least 3 weeks (31). Our results also showed that the risk of COVID-19 nucleic acid positivity was 2.1 times higher in patients who died than those who survived, indicating patients with SARS$\mathrm{CoV}-2$ prolonged positive was more likely to have poor outcome, which is consistent with the severe influenza virus infection (32). Exploring effective immune regulation and antiviral treatment to promote virus clearance might improve outcomes in critically ill COVID-19 patients with hypotension. 
There were differences in clinical characteristics and outcome between patients with early-onset hypotension and those with late-onset hypotension, which suggest there may be the difference of reason and pathophysiology between early-onset hypotension and late-onset hypotension. Evidence from a report showed that east respiratory syndrome (MERS)-CoV causes acute myocarditis (33), and a recent report on 138 COVID-19 patients showed that $7.2 \%$ of the patients developed acute cardiac injury, and critically ill patients were more likely to have cardiac injury (7). Our analysis indicated LDH, TNI, CK and CK-MB of the patients with early-onset hypotension on admission were all significantly higher than the values of the patients with lateonset hypotension. Thus, it is rational to hypothesize that early-onset hypotension might be mediated mainly by acute cardiac injury. However, the late-onset hypotension may be caused by other causes, such as secondary infection.

Our study has some limitations. First, for the retrospective study design, not all detailed data were acquired. Second, the critical state of the pandemic outbreak did not allow to performed hemodynamic monitoring. Third, there could well have been many patients who did not come to ICU for the limitations on medical resources and would have been missed. Last but not least, interpretation of our findings might be limited by missing data for some outcomes.

\section{Conclusions}

In this retrospective observational study of critically ill COVID-19 patients admitted to ICUs who have experienced a definite outcome, approximately nearly one third patients progressed to hypotension. More than three quarters of the patients with hypotension died at day 28 . The mortality was significantly higher than that in patients without hypotension. Compared with patients with lateonset hypotension, the 28-day mortality of patients with early-onset hypotension was significantly higher. Higher APACHE II score, lower $\mathrm{PaO}_{2} / \mathrm{FiO}_{2}$, elevated D-dimer, and HFNC and noninvasive mechanical ventilation were risk factors for death of critically ill COVID-19 patients with hypotension.

\section{Acknowledgments}

We shall thank all the doctors, nurses and clinical scientists who worked in the hospital during the period of patient recruitment as well as the patients who were involved in this study.

Funding: Support was provided solely from institutional and/or departmental sources, and they were Jiangsu Provincial Special Program of Medical Science (BE2019749) and National Science and Technology Major Project for Control and Prevention of Major Infectious Diseases of China (2017ZX10103004).

\section{Footnote}

Reporting Checklist: The authors have completed the STROBE reporting checklist. Available at https://dx.doi. org/10.21037/apm-20-2172

Data Sharing Statement: Available at https://dx.doi. org/10.21037/apm-20-2172

Conflicts of Interest: All authors have completed the ICMJE uniform disclosure form (available at https://dx.doi. org/10.21037/apm-20-2172). The authors have no conflicts of interest to declare.

Ethical Statement: The authors are accountable for all aspects of the work in ensuring that questions related to the accuracy or integrity of any part of the work are appropriately investigated and resolved. The study was conducted in accordance with the Declaration of Helsinki (as revised in 2013). The study was approved by Ethics Committee of Jin Yin-tan Hospital (KY-2020-10.02) and individual consent for this retrospective analysis was waived.

Open Access Statement: This is an Open Access article distributed in accordance with the Creative Commons Attribution-NonCommercial-NoDerivs 4.0 International License (CC BY-NC-ND 4.0), which permits the noncommercial replication and distribution of the article with the strict proviso that no changes or edits are made and the original work is properly cited (including links to both the formal publication through the relevant DOI and the license). See: https://creativecommons.org/licenses/by-nc-nd/4.0/.

\section{References}

1. Zhu N, Zhang D, Wang W, et al. A Novel Coronavirus from Patients with Pneumonia in China, 2019. N Engl J Med 2020;382:727-33. 
2. Qiu H, Tong Z, Ma P, et al. Intensive care during the coronavirus epidemic. Intensive Care Med 2020;46:576-8.

3. Zhou Y, Zhang Z, Tian J, et al. Risk factors associated with disease progression in a cohort of patients infected with the 2019 novel coronavirus. Ann Palliat Med 2020;9:428-36.

4. WHO. Coronavirus disease (COVID-19) outbreak. Accessed 16 May 2020. Available online: https://www.who.int

5. Huang C, Wang Y, Li X, et al. Clinical features of patients infected with 2019 novel coronavirus in Wuhan, China. Lancet 2020;395:497-506.

6. Guan WJ, Ni ZY, Hu Y, et al. Clinical Characteristics of Coronavirus Disease 2019 in China. N Engl J Med 2020;382:1708-20.

7. Wang D, Hu B, Hu C, et al. Clinical Characteristics of 138 Hospitalized Patients With 2019 Novel CoronavirusInfected Pneumonia in Wuhan, China. JAMA 2020;323:1061-9.

8. Chen N, Zhou M, Dong X, et al. Epidemiological and clinical characteristics of 99 cases of 2019 novel coronavirus pneumonia in Wuhan, China: a descriptive study. Lancet 2020;395:507-13.

9. Shi Y, Yu X, Zhao H, et al. Host susceptibility to severe COVID-19 and establishment of a host risk score: findings of 487 cases outside Wuhan. Crit Care 2020;24:108.

10. Grasselli G, Zangrillo A, Zanella A, et al. Baseline Characteristics and Outcomes of 1591 Patients Infected With SARS-CoV-2 Admitted to ICUs of the Lombardy Region, Italy. JAMA 2020;323:1574-81.

11. Bhatraju PK, Ghassemieh BJ, Nichols M, et al. Covid-19 in Critically Ill Patients in the Seattle Region - Case Series. N Engl J Med 2020;382:2012-22.

12. Yang $\mathrm{X}, \mathrm{Yu} \mathrm{Y}, \mathrm{Xu} \mathrm{J}$, et al. Clinical course and outcomes of critically ill patients with SARS-CoV-2 pneumonia in Wuhan, China: a single-centered, retrospective, observational study. Lancet Respir Med 2020;8:475-81.

13. Chen G, Wu D, Guo W, et al. Clinical and immunological features of severe and moderate coronavirus disease 2019. J Clin Invest 2020;130:2620-9.

14. Xie J, Wu W, Li S, et al. Clinical characteristics and outcomes of critically ill patients with novel coronavirus infectious disease (COVID-19) in China: a retrospective multicenter study. Intensive Care Med 2020;46:1863-72.

15. WHO. Clinical management of severe acute respiratory infection (SARI) when COVID-19 disease is suspected: Interim guidance. Accessed 16 May 2020. Available online: https://www.who.int

16. Khwaja A. KDIGO clinical practice guidelines for acute kidney injury. Nephron Clin Pract 2012;120:c179-84.

17. ARDS Definition Task Force; Ranieri VM, Rubenfeld GD, et al. Acute respiratory distress syndrome: the Berlin Definition. JAMA 2012;307:2526-33.

18. Mo P, Xing Y, Xiao Y, et al. Clinical characteristics of refractory COVID-19 pneumonia in Wuhan, China. Clin Infect Dis 2020. doi: 10.1093/cid/ciaa270.

19. Zhou F, Yu T, Du R, et al. Clinical course and risk factors for mortality of adult inpatients with COVID-19 in Wuhan, China: a retrospective cohort study. Lancet 2020;395:1054-62.

20. Sommer P, Lukovic E, Fagley E, et al. Initial Clinical Impressions of the Critical Care of COVID-19 Patients in Seattle, New York City, and Chicago. Anesth Analg 2020;131:55-60.

21. Corrales-Medina VF, Musher DM, Shachkina S, et al. Acute pneumonia and the cardiovascular system. Lancet 2013;381:496-505.

22. Shi S, Qin M, Shen B, et al. Association of Cardiac Injury With Mortality in Hospitalized Patients With COVID-19 in Wuhan, China. JAMA Cardiol 2020;5:802-10.

23. Kalil AC, Metersky ML, Klompas M, et al. Executive Summary: Management of Adults With Hospital-acquired and Ventilator-associated Pneumonia: 2016 Clinical Practice Guidelines by the Infectious Diseases Society of America and the American Thoracic Society. Clin Infect Dis 2016;63:575-82.

24. Xie J, Tong Z, Guan X, et al. Clinical Characteristics of Patients Who Died of Coronavirus Disease 2019 in China. JAMA Netw Open 2020;3:e205619.

25. Wu C, Chen X, Cai Y, et al. Risk Factors Associated With Acute Respiratory Distress Syndrome and Death in Patients With Coronavirus Disease 2019 Pneumonia in Wuhan, China. JAMA Intern Med 2020;180:934-43.

26. Arentz M, Yim E, Klaff L, et al. Characteristics and Outcomes of 21 Critically Ill Patients With COVID-19 in Washington State. JAMA 2020;323:1612-4.

27. Zou X, Li S, Fang M, et al. Acute Physiology and Chronic Health Evaluation II Score as a Predictor of Hospital Mortality in Patients of Coronavirus Disease 2019. Crit Care Med 2020;48:e657-65.

28. Klok FA, Kruip MJHA, van der Meer NJM, et al. Incidence of thrombotic complications in critically ill ICU patients with COVID-19. Thromb Res 2020;191:145-7.

29. Barrasa H, Rello J, Tejada S, et al. SARS-CoV-2 in Spanish Intensive Care Units: Early experience with 15day survival in Vitoria. Anaesth Crit Care Pain Med 2020;39:553-61. 
30. Ferrer M, Torres A. Noninvasive ventilation for acute respiratory failure. Curr Opin Crit Care 2015;21:1-6.

31. Corman VM, Albarrak AM, Omrani AS, et al. Viral Shedding and Antibody Response in 37 Patients With Middle East Respiratory Syndrome Coronavirus Infection. Clin Infect Dis 2016;62:477-83.

Cite this article as: Guo F, Xie J, Wu W, Li S, Hu M, Li J, Jiang L, Du B, Tong Z, Qiu H. Clinical characteristics and outcomes of critically ill patients with coronavirus disease 2019 with hypotension in China: a retrospective cohort study. Ann Palliat Med 2021;10(8):8536-8546. doi: 10.21037/apm-20-2172
32. Wang Y, Guo Q, Yan Z, et al. Factors Associated With Prolonged Viral Shedding in Patients With Avian Influenza A(H7N9) Virus Infection. J Infect Dis 2018;217:1708-17.

33. Alhogbani T. Acute myocarditis associated with novel Middle east respiratory syndrome coronavirus. Ann Saudi Med 2016;36:78-80. 


\section{Supplementary}

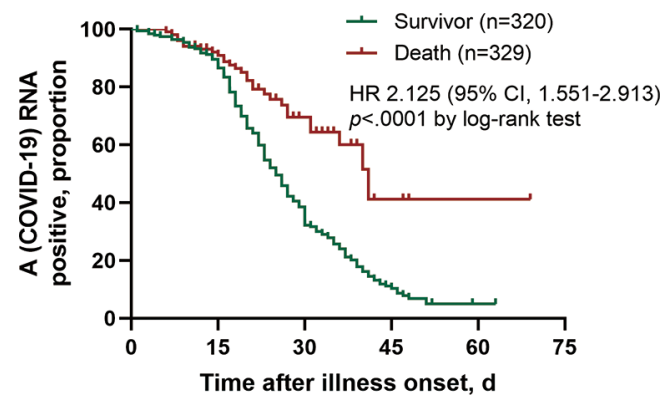

Figure S1 Virus shedding in hospitalized critically ill COVID-19 patients with hypotension who survived and died.

Table S1 Demographics and clinical characteristics of survivor and non-survivor

\begin{tabular}{|c|c|c|c|c|}
\hline Characteristic & All hypotension patients $(\mathrm{n}=240)$ & Non-survivor $(n=205)$ & Survivor $(\mathrm{n}=35)$ & P Value \\
\hline Age, median (IQR), yr & $67.0(60.0-73.5)$ & $68.0(62.0-75.0)$ & $57.0(50.0-69.0)$ & 0.00 \\
\hline Age $\leq 60, \mathrm{n}(\%)$ & $68(28.3)$ & $43(21.0)$ & $25(71.4)$ & 0.00 \\
\hline Age >60, n (\%) & $172(71.7)$ & $162(79.0)$ & $10(28.6)$ & \\
\hline \multicolumn{5}{|l|}{ Comorbidities, n (\%) } \\
\hline Hypertension & $166(69.2)$ & $155(75.6)$ & $12(34.3)$ & 0.00 \\
\hline Chronic heart disease & $35(14.6)$ & $31(15.1)$ & $4(11.4)$ & 0.57 \\
\hline Diabetes & $54(22.5)$ & $42(20.5)$ & $12(34.3)$ & 0.07 \\
\hline Solid malignancy & $8(3.3)$ & $7(3.4)$ & $1(3.0)$ & 0.87 \\
\hline \multicolumn{5}{|l|}{ Severity and time of hypotension (IQR) } \\
\hline APACHE II score on ICU admission & $13.0(9.0-17.0)$ & $13.0(10.0-17.0)$ & $10.0(8.0-14.0)$ & 0.00 \\
\hline SOFA score on ICU admission & $5.0(3.0-9.0)$ & $5.0(3.0-9.0)$ & $3.0(2.0-6.0)$ & 0.00 \\
\hline \multicolumn{5}{|l|}{ Symptoms on admission, n (\%) } \\
\hline Fever & $206(85.8)$ & 177 (86.3) & $29(82.0)$ & 0.59 \\
\hline Cough & $180(75.0)$ & $152(74.1)$ & $28(80.0)$ & 0.46 \\
\hline Shortness of breath & $173(72.1)$ & $149(72.7)$ & $24(68.6)$ & 0.62 \\
\hline Respiratory rate (beats/min) & $26.0(21.0-32.0)$ & $26.0(22.0-32.0)$ & $24.0(20.0-28.0)$ & 0.04 \\
\hline Mean arterial pressure $(\mathrm{mmHg})$ & 95.5 (83.3-103.7) & $96.3(83.0-105.0)$ & 92.7 (83.8-100.3) & 0.29 \\
\hline
\end{tabular}

Table S1 (continued) 
Table S1 (continued)

\begin{tabular}{|c|c|c|c|c|}
\hline Characteristic & All hypotension patients $(n=240)$ & Non-survivor $(n=205)$ & Survivor $(n=35)$ & P Value \\
\hline $\mathrm{PaO}_{2} / \mathrm{FiO}_{2}(\mathrm{mmHg})$ & $86.6(57.5-156.2)$ & $83.1(52.4-130.2)$ & $118.5(83.4-228.0)$ & 0.00 \\
\hline Leukocyte count $\left(\times 10^{9} / \mathrm{L}\right)$ & $10.4(7.9-14.8)$ & $10.4(7.9-14.8)$ & $10.0(7.4-15.5)$ & 0.95 \\
\hline Lymphocyte count $\left(\times 10^{9} / \mathrm{L}\right)$ & $0.5(0.3-0.8)$ & $0.5(0.3-0.8)$ & $0.5(0.3-0.8)$ & 0.19 \\
\hline Lactate dehydrogenase $(\mathrm{U} / \mathrm{L})$ & $543.0(402.0-812.0)$ & 570.5 (422.8-831.3) & $417.0(295.0-624.5)$ & 0.00 \\
\hline Alanine aminotransferase (U/L) & $33.50(21.1-51.0)$ & $33.0(21.0-54.5)$ & $34.0(23.0-64.0)$ & 0.77 \\
\hline Aspartate aminotransferase (U/L) & $38.0(27.3-63.8)$ & $39.0(28.0-64.5)$ & $31.0(22.0-57.0)$ & 0.16 \\
\hline C-reactive protein (mg/L) & 82.7 (43.5-150.9) & $86.0(45.7-156.3)$ & $62.2(24.4-90.3)$ & 0.01 \\
\hline D-dimer (ug/L) & $5.2(1.3-17.4)$ & $5.6(1.3-18.6)$ & $2.5(1.2-8.0)$ & 0.05 \\
\hline Creatinine $(\mu \mathrm{moL} / \mathrm{L})$ & $72.4(57.0-94.4)$ & $74.0(60.0-99.2)$ & $61.5(46.4-75.2)$ & 0.00 \\
\hline Troponin I (ng/mL) & $30.0(10.6-138.9)$ & $30.0(10.2-155.0)$ & $30.0(13.4-93.8)$ & 0.88 \\
\hline Creatine kinase $(\mathrm{ng} / \mathrm{mL})$ & $98.0(49.8-246.5)$ & $102.0(52.0-273.0)$ & $65.4(38.0-132.0)$ & 0.03 \\
\hline \multicolumn{5}{|l|}{ Therapy, and outcome } \\
\hline Antiviral therapy, $\mathrm{n}(\%)$ & $177(73.8)$ & $150(73.2)$ & $27(77.1)$ & 0.62 \\
\hline Glucocorticoid therapy, n (\%) & $148(61.7)$ & $129(62.9)$ & $19(54.3)$ & 0.33 \\
\hline IV immunoglobulin therapy, n (\%) & $215(52.8)$ & $103(50.2)$ & $23(65.7)$ & 0.09 \\
\hline CRRT, n (\%) & $64(26.7)$ & $56(27.3)$ & $8(22.9)$ & 0.58 \\
\hline Virus Shedding, $\mathrm{n}(\%)^{\star}$ & $28(11.7)$ & $16(7.8)$ & $12(34.3)$ & 0.00 \\
\hline ICU length of stay, (IQR), d & $8.0(5.0-14.0)$ & $8.0(5.0-13.0)$ & $33.0(27.3-40.5)$ & 0.00 \\
\hline Hospital length of stay, (IQR), d & $12.0(8.0-21.0)$ & $11.0(7.0-18.5)$ & $33.0(27.3-40.5)$ & 0.00 \\
\hline
\end{tabular}

*, All shock patients $(n=73)$, Non-survivor $(n=34)$, Survivor $(n=39)$. COPD, chronic obstructive pulmonary disease; APACHE II, Acute Physiology and Chronic Health Evaluation II; SOFA, Sequential Organ Failure Assessment; $\mathrm{PaO}_{2} / \mathrm{FiO}_{2}$, arterial partial pressure of oxygen/ fraction of inhalation oxygen; HFNC, high-flow nasal cannula; NIV, noninvasive mechanical ventilation; IMV, invasive mechanical ventilation; CRRT, continuous renal replacement therapy. 